\title{
Operative techniques to reduce anastomotic recurrence in Crohn's disease
}

\author{
D. Selvakumar ${ }^{1}$ (D) A. E. Sayers ${ }^{2} \cdot$ S. R. Brown ${ }^{2} \cdot$ L. Hancock $^{1}$
}

Received: 3 December 2021 / Accepted: 5 January 2022 / Published online: 27 January 2022

(c) Crown 2022

In this video, we demonstrate two operative techniques used to reduce the risk of anastomotic recurrence in Crohn's disease.

It has been suggested that the mesentery is a pathological driver of disease recurrence in Crohn's and performing a radical mesenteric excision has shown promising results in reducing rates of anastomotic recurrence $[1,2]$. The first section of the video demonstrates a standardised technique to perform a radical mesenteric excision during an ileocaecal resection for terminal ileal Crohn's disease.

The Kono-S is an antimesenteric, functional, end-to-end, handsewn anastomosis that has been shown to be a safe and effective technique to reduce the risk of anastomotic recurrence $[3,4]$. In the second part of the video, we demonstrate a step-by-step approach to performing this as part of an ileocaecal resection, with primary anastomosis, for terminal ileal Crohn's disease.

Supplementary Information The online version contains supplementary material available at https://doi.org/10.1007/s10151-022-02569-1.

Acknowledgements Medical illustration department, Sheffield Teaching Hospitals NHS Foundation Trust, for capturing the operative footage. Medical illustration department, Manchester University NHS Foundation Trust, for producing the illustrations used in this video.

\section{Declarations}

Conflict of interest The authors declare that they have no conflict of interest.
Ethical approval This study did not require an ethics committee approval however explicit consent was obtained from patients for video recording and publication.

Informed consent All patients received an explanation of the procedure and provided informed consent.

Open Access This article is licensed under a Creative Commons Attribution 4.0 International License, which permits use, sharing, adaptation, distribution and reproduction in any medium or format, as long as you give appropriate credit to the original author(s) and the source, provide a link to the Creative Commons licence, and indicate if changes were made. The images or other third party material in this article are included in the article's Creative Commons licence, unless indicated otherwise in a credit line to the material. If material is not included in the article's Creative Commons licence and your intended use is not permitted by statutory regulation or exceeds the permitted use, you will need to obtain permission directly from the copyright holder. To view a copy of this licence, visit http://creativecommons.org/licenses/by/4.0/.

\section{References}

1. Coffey CJ et al (2018) Inclusion of the mesentery in ileocolic resection for Crohn's disease is associated with reduced surgical recurrence. J Crohns Colitis 12(10):1139-1150. https://doi.org/ 10.1093/ecco-jcc/jjx187 (PMID: 29309546)

2. Zhu Y, Qian W, Huang L, Xu Y, Guo Z, Cao L, Gong J, Coffey JC, Shen B, Li Y, Zhu W (2021) Role of extended mesenteric excision in postoperative recurrence of Crohn's colitis: a singlecenter study. Clin Transl Gastroenterol 12(10):e00407. https://doi. org/10.14309/ctg.0000000000000407 (PMID:34597277;PMCI D:PMC8483874)

3. Kono T, Fichera A, Maeda K, Sakai Y, Ohge H, Krane M, Katsuno H, Fujiya M (2016) Kono-S anastomosis for surgical prophylaxis of anastomotic recurrence in Crohn's disease: an international
D. Selvakumar

Deepak.selvakumar@postgrad.manchester.ac.uk

1 Department of General Surgery, Manchester University NHS Foundation Trust, Manchester, UK

2 Department of General Surgery, Sheffield Teaching Hospitals NHS Foundation Trust, Sheffield, UK 
multicenter study. J Gastrointest Surg 20(4):783-790. https://doi. org/10.1007/s11605-015-3061-3 (PMID: 26696531)

4. Shimada N, Ohge H, Kono T et al (2019) Surgical recurrence at anastomotic site after bowel resection in Crohn's Disease: comparison of Kono-S and end-to-end anastomosis. J Gastrointest Surg 23:312-319. https://doi.org/10.1007/s11605-018-4012-6
Publisher's Note Springer Nature remains neutral with regard to jurisdictional claims in published maps and institutional affiliations. 